\title{
The Experience of Watching: \\ Place Defined by the Trinity of \\ Land-, Sea-, and Skyscape
}

\section{Daniel Brown}

\begin{abstract}
The interpretation of astronomically-orientated ancient sites has frequently led to the conclusion that an astronomy cast needs to exist: a group that is thought to be highly educated as apparent within discussions and comments with researchers even if never published. This group within an ancient society would have a deeper knowledge of the movements of the Sun, Moon and stars derived through observations and analysis similar to modern day scientific methodology and not accessible to the un-initiated. However, cultural astronomy has started to overcome this mistake by describing such sites not as observatories but as places where a certain phenomenon can be experienced and watched.

This paper will discuss this act of watching and how it is closely linked to a definition of place by introducing the notion of the dialectical image. The triad of land-, sea-, and skyscape offers common themes and characteristics that allow the watcher to critically negotiate the surroundings and experience the place by dwelling therein. All three form a trinity and are actually part of one skyscape that invokes feelings, illustrates tensions, and asks for action. Experiencing this unity is essential to watching. At this stage there is no deeper astronomical knowledge required that is only accessible to the initiated few. Cosmic cycles that manifest themselves through the motions of the Sun, Moon and stars as well as seasonal and tidal rhythms become obvious to everyone. Skyscapes at astronomically-orientated sites capture this meaning. When stepping back from observing, and engaging in watching, the meaning can be recaptured in the trinity of land-, sea-, and skyscape.
\end{abstract}

\section{Introduction}

The following article is an analysis of land-, sea-, and skyscape as seen from the author's perspective and to some extent discussed by Silva. ${ }^{1}$ To

\footnotetext{
${ }^{1}$ Fabio Silva, 'The role and importance of the sky in archaeology: an introduction' in Fabio Silva and Nicholas Campion (eds), Skyscapes: The Role and Importance of the Sky in Archaeology (Oxford: Oxbow Books, 2015), pp. 1-8.
}

Daniel Brown, 'The Experience of Watching: Place Defined by the Trinity of Land-, Sea-, and Skyscape', Culture and Cosmos, Vol. 17, no. 2, Autumn/Winter 2013, pp. 5-24.

www.CultureAndCosmos.org 
enable the reader to critically engage with this article it is helpful to outline the background of the author and the motivation behind his work.

The author is a trained astronomer who has carried out several astronomy-teaching activities in rural settings and embraced the surroundings as part of the activities delivered. Such additional activities initially enriched the strictly astronomy-related teaching through exploring the surrounding landscape with its geological and archaeological features or visiting unique trades being carried out at bell foundries or by basket makers. In his more recent work, he is fully integrating the outdoor surroundings and utilising it as a classroom in which astronomy, mathematics and physics can be experienced. The topic of light pollution lies close to the author's heart and his approach to light pollution education integrates the cultural heritage and the place experience. Within this context and his work on the Astronomy in the Park project, the views and arguments presented here have been developed. ${ }^{2}$

The movement away from the narrow focus of astronomy that takes place only within the observatory to astronomy experienced in a real place within a landscape has been the first step to understanding place and possibly offering a solution to some typical dilemmas faced in modern archaeoastronomy.

In the past decades archaeoastronomy has become more acceptable to many, as Ruggles points out, by placing its finding on a sound and solid basis of statistical analysis. ${ }^{3}$ The social relevance of these results have only slowly been integrated in recent years. Even authors such as Harding, who coined the term skyscape for the first time in an archaeoastronomy context, still default to statistical methods. ${ }^{4}$ Orientations and alignments surveyed at ancient monuments are gathered together into representative groups. Statistical analysis within these groups allows for building up an argument for the intentionality of a measured alignment, thereby ruling out pure chance alignments. However, such a method can only work if one chooses the correct examples in terms of a typology and regional cohesion; i.e., grouping and if there are sufficient examples present. In many cases there

\footnotetext{
${ }^{2}$ Daniel Brown, 'How can Higher Education Support Education for Sustainable Development? What can Critical Place-Based Learning Offer?' (MA Dissertation, University of Nottingham, 2013).

${ }^{3}$ Clive L. N. Ruggles, Astronomy in prehistoric Britain and Ireland (Princeton: Yale University Press, 1999), p. 76.

${ }^{4}$ Jan Harding, Ben Johnson, and Glyn Goodrick, 'Neolithic Cosmology and the Monument Complex of Thornborough, North Yorkshire', Archaeoastronomy 20 (2006): p. 50.
}

Culture and Cosmos 
might only be one single but unique monument present, for example Stonehenge. But even when working with a large enough group of monuments that have all been built by the same cultural group, the result is a reliable alignment only. Alignment will be either an azimuth or, using the local horizon, a declination, but it will not tell us what the meaning and motivation was behind establishing this alignment. An alignment might point towards the rising or setting point of the Sun on the horizon at some time during the year. This may also coincide with a Moon rising or setting as well as some of the bright stars. But the alignment alone is not enough to indicate which one of these was the intended target. The situation is made even worse by realising that high-precision data analysis is being used, giving alignments with well-defined error bars and applying it to buildings constructed by societies that did not either have the technology to achieve high precision or possibly did not value precision that much. ${ }^{5}$ This could mean that an alignment might only roughly point out an intended setting of a star, since the builder of the monument would know what to anticipate. All these are challenges deriving from an inability to extract the meaning behind an alignment using pure statistical analysis and alignment hunting.

Here, it is proposed that exploring the place experience at the site of a detected alignment can help to understand the meaning of it. It will move away from the narrow and scientific term of observation and use the more holistic term of watching. Watching the skyscape along an alignment allows an engagement with a place. This is possible through understanding the landscape surrounding the viewer in a phenomenological way, as illustrated by Tilley, and in a next step as a dialectical landscape that draws you in and communicates with you. ${ }^{6}$ To show this, an elaboration is required upon what a place actually is and how time is an inherent part of it. This is followed by the description of the dialectical image upon which the idea of a dialectical landscape has been modelled. The view into the Derwent valley at Gardom's Edge in the Peak District, where the author has worked, will help to illustrate the concept of a dialectical landscape that will then allow formulating how to fully engage and dwell in a place and a landscape. Finally, the focus is drawn upon the seascape used as an

\footnotetext{
${ }^{5}$ Fabio Silva, 'A Tomb with a View: New Methods for Bridging the Gap between Land and Sky in Megalithic Archaeology', Advances in Archaeological Practice: A Journal of the Society for American Archaeology 2, no. 1 (2014): p. 27.

6 Christopher Tilley, A Phenomenology of Landscape: Places, Paths, and Monuments (Oxford: Berg, 1994).
} 
introduction to becoming one with the place and realising that land-, sea-, and skyscape as well as the viewer are all a unity.

\section{The Place Experience}

Since place and its experience is essential in understanding a landscape and becoming more aware of the meaning of a possible alignment, this is the point where the term place needs to be described and the author's view on what defines a place needs to be outlined.

Place is not identical to a location on a map pointing out where one lives, for example. There is a big difference between: a Bed and Breakfast accommodation frequented while working away and the home lived in since birth. Both are places where one resides and should be similar; however the first usually has no personal connection to oneself. It will be used for the sole purpose of sleeping and having breakfast and it would never be described as a place at which one lived but rather where one stayed. The home is a completely different experience. One lives at home. Every part of it is imbued with memories, feelings and meanings. One has created part of it and is aware of its history and location within a wider community of neighbours and streets.

The description of place throughout Tuan's book Space and Place implies it being filled with meaning and is seen by Heidegger as a locality at which one dwells. ${ }^{7}$ As argued by Heidegger, dwelling is a process, in which the surroundings are explored and engaged with, allowing a reflection upon one's existence. When looking upon one's home one can see into one's past and try to make sense of what it means to exist or to be. This might even extend to exploring the past of the house and plot upon which it was built. It might appear as described in Hussey's translation of Aristotle's work, Physics III and IV, that a place has boundaries similar to a box in which all these meanings and feelings might be collected, but it is a far more fluid concept. ${ }^{8}$ Ingold points out that our paths through our lives and the landscape over time intersect and loop around, causing encounters and revisiting of past memories. ${ }^{9}$ These real or imaginary journeys will tangle and create localities without defining a boundary. Such a view picks up on some of the previously mentioned interconnections a place might

\footnotetext{
${ }^{7}$ Yi-Fu Tuan, Space and Place: The Perspective of Experience (University of Minnesota Press, 1977); Martin Heidegger, Being and Time (Harper Perennial Modern Classics, 2008): pp. 78-90.

${ }^{8}$ Aristotle, Physics, Books III and IV, trans. Edward Hussey (Oxford: Oxford University Press, 1983), IV, pp. 212a20-21.

${ }^{9}$ Tim Ingold, Lines: A Brief History (London: Routledge, 2007), p. 100.

Culture and Cosmos
} 
have with its surrounding, other individuals and history. It also leads on to the important fact that place, though seemingly a purely space-related concept, is defined by and has to contain time. Without time, a path could not be followed and memories could not be gathered. Only time helps us to inscribe the rhythms in our wanderings and cycles in our lives while carrying out our everyday tasks. ${ }^{10}$ Bergson argues that without time there cannot be emotion and feelings. ${ }^{11}$ But this time is not the one described by atomic clocks but rather what Sorokin and Merton describe as social time loaded with emotions and memories. ${ }^{12}$ The process of drawing one's path is made up of many tasks, described by Ingold in his idea of taskscape, and will evoke feelings and interactions with a locality so that both together develop a meaning and a place. ${ }^{13}$

Therefore, it is essential to become aware of time so that one can dwell in a Heideggerian sense, thereby realising that both space and time come together to create a place. ${ }^{14}$ The time experience can be gathered at a place by revisiting it over many seasons or over an entire day noticing subtle changes and rhythms as one becomes more aware of the place. Such an engagement would not be focused upon a singular event or single object but has to be open to the entire setting and context of the surroundings at different times. It would be inappropriate to describe this activity or indeed task as observation; it is more likened to watching. The Oxford Dictionary, indicative of a common view, links observing closely to a scientific approach where something is detected and followed closely. ${ }^{15}$ It also contains strong connotations of anticipation, an emotional response heightening awareness. Watching however is defined as looking or looking

${ }^{10}$ Henri Lefebvre, Rhythmanalysis: Space, Time and Everyday life (London: Continuum, 2004), p. 8.

${ }^{11}$ Henri Bergson, Time and Free Will: An Essay on the Immediate Data of Consciousness (New York : Cosimo Classics, 2008), p. 231.

${ }^{12}$ Pitirim A. Sorokin and Robert K. Merton, 'Social time: a methodological and functional analysis', American Journal of Sociology (1937): p. 622.

${ }^{13}$ Tim Ingold, 'The temporality of the landscape', World Archaeology 25, no. 2 (1993): p. 157.

14 Daniel Brown, 'Skyscapes: Present and Past-From Sustainability to Interpreting Ancient Remains', in Fabio Silva and Nicholas Campion (eds), Skyscapes: The Role and Importance of the Sky in Archaeology. (Oxford: Oxbow Books, 2015), pp. 32-41.

${ }^{15}$ Oxford Dictionary at http://www.oxforddictionaries.com/definition/english/observe?q=observe, [Accessed 28 March 2014]. 
out for something over a period of time and not focussing necessarily at a specific subject of interest. ${ }^{16}$ Only watching includes explicitly in its definition the passage of time. The linking of time to watching becomes even more apparent when noting that its noun is the description of our everyday timepiece- a watch - that helps us to follow the passage of time. And here lies possibly the core of some of archaeoastronomy's recent challenges. Such an experience cannot be accessed through a one-off visit to observe an alignment of only this very specific aspect of a monument. It is this typical modern scientific approach, alien to ancient societies, that blinds us from discovering a meaning of an alignment and is far from the holistic task of watching.

\section{A Dialectical Landscape}

Places containing monuments and their possible alignments are embedded within a much larger network of experiences, emotions and their surroundings. These surroundings are what are termed as landscapes and might be, as in the case of place, associated too closely to the concept of space alone. Here the theoretical concept of a dialectical landscape will be developed, followed by learning how to experience and communicate with a landscape.

\section{The Theoretical Outline}

The typical places analysed in archaeoastronomy are usually located within a landscape. The following will give a brief overview of the author's understanding of landscape in the art historian context. It is in no way complete and represents the author's discourse with landscape paintings.

The word landscape has its roots in the Anglo-Saxon equivalent of the German word Landschaft, denoting a small patch of a larger feudal estate. ${ }^{17}$ The term fell out of use until it became frequented in the arts when referring to depicting scenery on land. ${ }^{18}$ In the medieval worldnaturalistic scenes were usually a backdrop to the main topic of the painting. In the Renaissance they became more elaborate and important in the overall

\footnotetext{
${ }^{16}$ Oxford Dictionary at http://www.oxforddictionaries.com/definition/english/watch?q=watch, [Accessed 28 March 2014].

${ }^{17}$ Barbara Bender, 'Place and Landscape', in Chris Tilley et al. (eds), Handbook of Material Culture (London: Sage, 2006): p. 307.

${ }^{18}$ Anon., 'Brief History of the Landscape Genre', J. Paul Getty Museum at http://www.getty.edu/education/teachers/classroom_resources/curricula/landscape s/background1.html, [accessed: 13 May 2014].
}

Culture and Cosmos 
message conveyed by the painter, for example in the works by Leonardo Da Vinci. ${ }^{19}$ However, the land was never the motive for paintings until towards the seventeenth century when Dutch painters made this art form popular. In the following century it spread to other European countries and watercolour paintings of landscapes became an English speciality. In the nineteenth century, as romanticism peaked and the industrial revolution was gathering pace, landscape paintings were already popular outside of Europe and were becoming the dominant art. They offered an opportunity to express tensions and hopes arising in artists such as Turner, Cole and Friedrich. Already the recognition of land as the main motive by Dutch painters, as stated by Clark, was born from the political religious background of a protestant middle class. ${ }^{20} \mathrm{~A}$ deeper analysis of landscape painting is further motivated for example by the attempt to capture the sublime in giant landscapes created by the Hudson River School and the influence of nationalism on landscape painting trying to describe the national character. Ruskin is one author in whom there has been renewed interest in recent times through the work of Clark, especially in the context of the interaction of humans and nature. ${ }^{21}$ The reading of landscapes used by Ruskin and described in Cosgrove was furthered by others such as Meining. ${ }^{22}$ Furthermore, Berger and Williams underline that the analysis has to go beyond a philosophical discussion and must include society and the economy. ${ }^{23}$

One approach to analysing the landscapes outlined in more detail here was proposed by Cosgrove and Daniels. ${ }^{24}$ Through iconography and a

19 Anon., 'A Brief History of Landscape Painting: Holland Berkley and Igor Medvedev', Park West Gallery at http://www.parkwestgallery.com/archives/14848 [accessed: 13 May 2014].

${ }^{20}$ Kenneth Clark, Landscape into Art (Harmondsworth: Penguin Books, 1956), p. 43.

${ }^{21}$ Clark, Landscape into Art.

22 Denis E. Cosgrove, 'John Ruskin and the geographical imagination', Geographical Review (1979): pp. 43-62; D. W. Meining, 'Reading the landscape: An Appreciation of W. G. Hoskins and J. B. Jackson', in D. W. Meining (ed.), The Interpretation of Ordinary Landscapes (New York: Oxford University Press, 1979): pp. 195-244.

${ }^{23}$ John Berger, Ways of Seeing (Penguin UK, 2008); Raymond Williams, The country and the city, Vol. 423 (New York: Oxford University Press, 1975): p. 120.

${ }^{24}$ Denis Cosgrove and Stephen Daniels, The Iconography of Landscape: Essays on the Symbolic Representation, Design and Use of Past Environments (Cambridge: Cambridge University Press, 1989), p. 5. 
structure of symbols related to power they try to understand the different layers of meaning. They furthermore extend these ideas to analyse landscape gardens, installations and landscapes in general. They see a landscape as a stage on which power struggles are visible. They illustrate tensions and conflicts between their usage and conservation. Given their starting point of landscape painting, it is understandable that they access landscapes through physical localities alone placed into a pre-existing setting. But it will become apparent that landscape is far more than just a collection of physical symbols.

Dwelling and discovering one's being requires a dialectic discourse to take place between what one is and is not (A or not $\mathrm{A}$ ). When viewing a landscape one sees these two extremes ever present-for example in conserving moorland or mining its resources. ${ }^{25}$ This dialectic conflict has as an outcome a synthesis apparent in the current landscape; it might be different to our own view of how it should be; at this point one realises that when engaging with these symbols of power one is drawn in and begins to develop a personal conclusion. Initially the process of dialectic was defined as the compromise between just two solutions, A and not A. The outcome would be a single answer that could then be used for another dialectic discourse that might come closer to the truth of the problem in each step of this Hegelian ladder, as critically discussed by Kaufmann. ${ }^{26}$ However, this process has several shortcomings that a dialectical image and, following on, the dialectical landscape can overcome:

- When posing the problem there might not be the apparent polarity of solutions. There might be several options that go beyond the pure A and not A. It can oversimplify matters or introduce biases that would guide the true solution, especially when applying the modern western scientific methodology that aims at reduction in order to gain a generalised hypothesis that can be repeatedly proven or disproven in a particular context and at any time, always achieving the same answer.

- The concept of a final truth is problematic in itself. Is it at all present? Could there be many different truths out there, one for each individual? Might the true solution of a problem depend upon time and develop into

\footnotetext{
${ }^{25}$ D. A. Gruenewald, 'The Best of Both Worlds: A Critical Pedagogy of Place', Educational Researcher 32, no. 4, (2003): p. 4.

${ }^{26}$ Walter Arnold Kaufmann, Hegel: A Reinterpretation (South Bend: University of Notre Dame Press, 1978), Ch. 37.

Culture and Cosmos
} 
something different as time passes by? Is the solution to the dialectic discourse always a step into the right direction to discover the solution to a problem? Bear in mind the different usages of many groups of many sites of archaeo-astronomical interest, each claiming to have uncovered the real meaning or truth of a site. For example, Stonehenge as offering a place of public worship for the Druids or an innovative and alternative venue for a solstice event for an estimated 12,500 visitors that had a mixed interpretation of Stonehenge. ${ }^{27}$ Other usages might include stone circles, such as The Nine Ladies on Stanton Moor, as examples of cultural heritage and linking its value to the dark sky agenda, utilising its perceived energy to support meditation and healing, or using it as a symbol for environmental damage caused through quarrying. ${ }^{28}$ This is true even in the scientific community where hypotheses offer a hiding place for the constraints forced upon us by a certain methodology. In terms of a true methodology this can be seen in the derogative critique of Fleming who describes the work inspired by, as he terms it, hyper-interpretive narratives and phenomenology as 'rhetoric and the uncritical acceptance of the output of sometimes fevered imaginations ${ }^{29}{ }^{29}$ In particular, the phenomenological landscape approach proposed by Tilley when analysing the megalithic monuments of the southwest of Wales in Phenomenology of the Landscape triggered Fleming's response, since it was seen to be going beyond the evidence, identifying more than one significant landscape feature important for a monument's location, and overall attempting a more general interpretation. ${ }^{30}$ Tilley responds by indicating that Fleming

\footnotetext{
${ }^{27}$ Robert J. Wallis and Jenny Blain, 'Sites, Sacredness, and Stories: Interactions of Archaeology and Contemporary Paganism', Folklore 114, no. 3 (2003): p. 309.

28 Daniel Brown, Fabio Silva and Rosa Doran, 'Archaeo-Astronomy and Education', Anthropological Notebooks 19 (Supplement), (2013): pp. 518; Kal, Nine Ladies P2-A Healing Ceremony at http://www.hedgedruid.com/2008/09/nine-ladies-p2-a-healing-ceremony/ [Accessed 12 May 2014]; John Vidal, 'Protesters Dig in to Save Landscape from Quarry: “It'll cost millions to get us out”', Guardian, 14 February 2004, available at http://www.theguardian.com/environment/2004/feb/14/activists.conservation [accessed 12 May 2004].

29 Andrew Fleming, 'Post-processual Landscape Archaeology: A Critique', Cambridge Archaeological Journal 16, no. 3, (2006): p. 279.

30 Christopher Tilley, Interpreting Landscapes: Geologies, Topographies, Identities; Explorations in Landscape Phenomenology 3 (Left Coast Press, 2010), pp. 471-81.
} 
never engaged with the philosophical, theoretical, or conceptual issues of the phenomenology applied to landscape. Especially illustrative toward the concept of a single truth is Tilley's statement regarding Fleming's criticism that 'instead of a nuanced and multifaceted perspective on landscape, a simple black-and-white perspective in which there can only be one reason why a specific location might have significance rather than many' is used and '[Tilley's] approach becomes constituted as Other [and amounting] to a parable of good versus evil'. ${ }^{31}$

- The process of arriving at the final truth is defined by a clear and linear combination of dialectic discourses. One has to follow them in this exact order as predefined by a previous individual. Here this individual has power over guiding you to their real truth. When dealing with an alignment this might be seen as the initiated caste of astronomers of an ancient society. Only the initiated would be aware of this only true path of meaning.

The theoretical concept of the dialectical image-a general concept from which the dialectical landscape will follow, defined by the author in the next paragraph — was proposed and described by Benjamin throughout his correspondence with Adorno and stated by Auerbach. ${ }^{32}$ It is an attempt at solving these problems. It breaks with the linear approach of reasoning outlined above by offering the possibility to negotiate a (hypothetical) image constructed through a constellation of moments. Whereby several possible arguments, facts, impressions, feelings and moments in general are perceived in unity, for example on a two dimensional surface of a painting. There is no path to follow, no pre-defined overlaid structure similar to a mind map, and even the concept that a single object is perceived on its own does not hold. In a painting the viewer encounters everything at once. As a consequence, the image allows an individual to see all possible solutions and factors relevant to him at the same time in an interconnected manner or constellation. A path can be woven and negotiated in any way. The whole idea of presenting it without a sequence allows seeing things in context and seeing indeed the bigger picture. The

${ }^{31}$ Tilley, Interpreting Landscapes, p. 478, 481.

32 Walter Benjamin, On the Concept of History (New York: Classic Books America, 2009); Walter Benjamin, 'The Correspondence of Walter Benjamin, 1910-1940', ed. Gershom Scholem and Theodor W. Adorno and trans. Manfred R. Jacobson and Evelyn M. Jacobson (Chicago: University of Chicago Press, 1994); Anthony Auerbach, 'Imagine No Metaphors: The Dialectical Image of Walter Benjamin’, Image \& Narrative 18 (2007).

Culture and Cosmos 
constellation of moments might be different for each and every one. Removing the constraints imposed by structures of power will, in Benjamin's words, offer a 'revolutionary chance in the fight for the oppressed past' and empower the individual. ${ }^{33}$ The moments as part of a constellation are never time independent conclusions of an individual, but are fleeting and come and go, or remain as more significant for an individual making this dialectical image. The constellation will alter adapting to the times and changes present in both the individual as well as society.

Applying this theoretical concept to a landscape creates a dialectical landscape. Here the described moments can be identified to some extent by objects seen in the landscape that symbolise certain characteristics of a landscape. For example a quarry might represent the natural resources defining a landscape. But moments are entities in time and are far more than physical objects. The above-mentioned quarry might be overgrown and represent the current status of mining in the region or cause the viewer to feel delighted in how nature has started to reclaim this patch of landscape as it might have done in many instances before. The moments are meaning and emotions unlocked in the rhythmic flow of time. They are part of the package a viewer of the landscape has brought with them as memories. The viewer's baggage manifests itself in a landscape that acts as a pointer towards times gone by. The image is only used to visualise the concept. It contains far more than just visual stimuli to include touch, smell and hearing. All senses come together to present an array of moments loaded with emotions and causing emotions by themselves.

\section{Applications in a Landscape}

At this point it should be noted that reading this article in the seclusion of one's study or listening to it being read in a grey concrete lecture theatre might not be the best environment in which to follow the ideas presented here. It would be a far better option to walk or, even better, wander through your local neighbourhood or countryside. Such drifting and becoming lost is an approach described by Coverley as psychogeography. ${ }^{34}$ One becomes a flanêur, feeling the personal meaning of the landscape and how places have a distinct emotional impact on us. ${ }^{35}$ To capture this notion the author

${ }^{33}$ Benjamin, On the Concept of History, p. 396; Tilley, A Phenomenology of Landscape, p. 40.

${ }^{34}$ Merlin Coverley, Psychogeography (Oldcastle Books Ltd, 2010), pp. 9-30.

${ }^{35}$ Walter Benjamin, Harry Zohn and Q. Hoare, Charles Baudelaire: A Lyric Poet in the Era of High Capitalism (London, 1973), p. 54. 
would like to present a brief description of what a view into the landscape gathered at a frequently visited location might offer. This location was chosen since it is part of a landscape visited in many different contexts as well as to develop the author's approach to phenomenology. It is lacking in covering all the aspects raised above but should be seen as a starting point for the reader's own exploration and wanderings. It also forces the reader to follow the author's winding trail across the picture with moments inspired through the presence of many aspects and emotions simultaneously. All this cannot be described in a comprehensive narrative but should encourage the reader to go and experience the dialectical landscape themselves and see where their journey leads them.

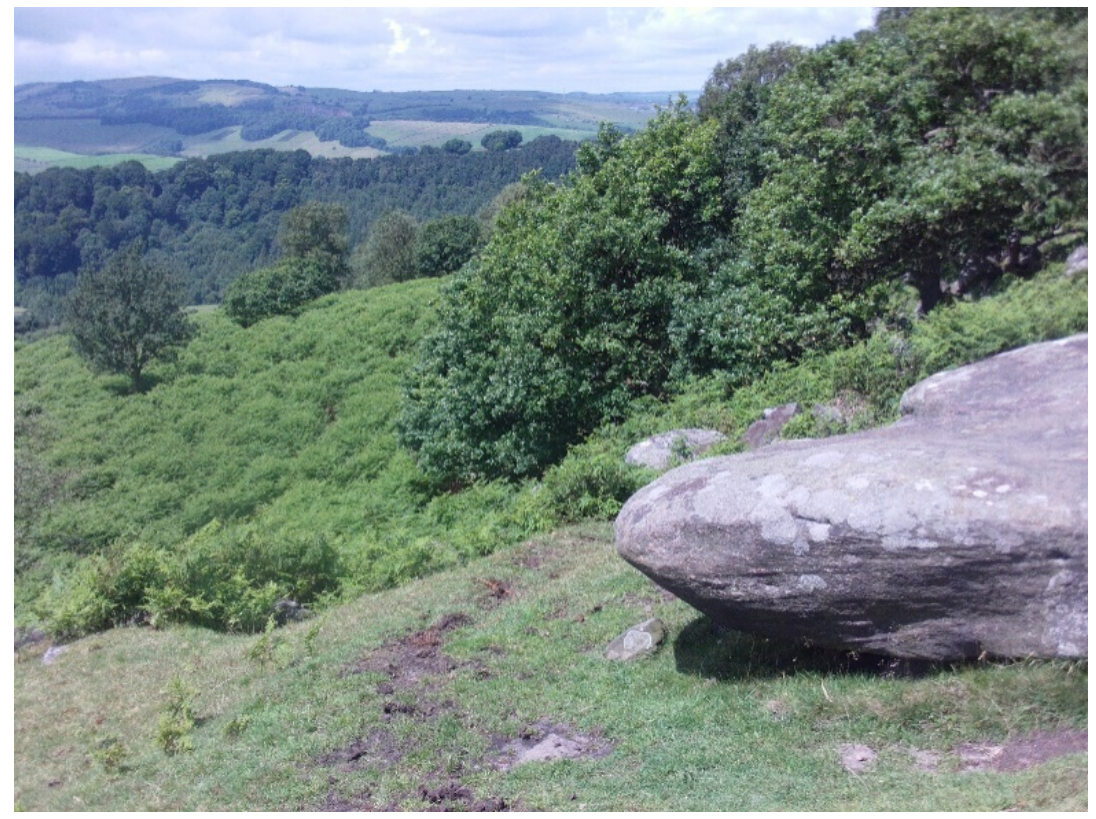

Fig. 1. Views into the Derwent Valley at Gardom's Edge, Peak District, UK. The image contains many physical objects possibly representing power and time as well as triggered emotional responses.

The imaginary journey of the author takes place in a view captured in parts in Figure 1. The image shows the landscape at Gardom's Edge in the Peak District as a ridge containing a large amount of cultural heritage:

Standing at this point I gather the first view into the Derwent valley and the expansive horizon framing the rolling clouds. In the distance I can note a

Culture and Cosmos 
disused quarry illustrating how we have mined this region to access its resources. Such activities have left behind scars in the landscape that are slowly recovering. The mining itself did not take into account the interaction with nature nor was it sustainable. As such it acts as a reminder how [humans] can destroy nature. However in close proximity I can notice two rectangular fields where one can just make out the letters $E$ and $R$. These are a plantation created to honour the Queen. They are a mark in the landscape clearly visible for miles and stating a cultural aspect of our current society in a much more sustainable fashion. Both mining and commemorative plantations are solutions to how humans interact with nature in recent times, and specifically in context of colonisation and rehabilitation. ${ }^{36}$

In the foreground of the image two muddy paths are visible, one of which is an ancient track used centuries ago prior to the old toll road below in the valley. If I follow the path down the ridge entering the denser woodland, a Victorian Smithy awaits, moss overgrown and in the deep cool shadows of the trees. Surely something one might overlook when walking along this route. Here I cast my mind back at several school classes guided down this route and their explorations of the surrounding landscape. But taking the path up the ridge will lead along a much more recent path used by some walkers to enter Gardom's Edge and Birchen Edge. This fork represents the entrance onto the ridge and also a short respite while walking up the incline.

The junction itself is marked by a rather large rock. This is sedimentary sandstone, Millstone Grit, the bones of this landscape, shaping and forming its outcrops and slopes. This rock reveals what was here millions of years ago and opens up our perception of time exploration on a much larger scale. It also was the starting point for my journey towards geology and analysing sedimentary sandstone, a topic quite far removed from my usual work. The two paths are both recent and centuries old, created through the human rhythmic task of walking. The rock represents times before humans were part of this landscape. The distant views reveal disused quarries and plantations that are both recent results of human interaction with the landscape: one fading away slowly but surely as its creative rhythm dies down while the other reveals powers present in our society through its continuous up keeping.

At this time and location I can also draw upon my own experience of time: how this was the point at which dawn revealed a rising mist and the still silent main road in the valley at an equinox visit to the site after having ventured up hill in darkness; how the dense falling snow inhibited any views beyond 10 meters and forced the group of international school teachers to turn back down towards the shelter of the inviting Inn at the car park. Such musings might then lead on to me thinking: we have picked a good time to come here.

Again, the train of thought might be drawn back towards our impact on nature and sustainability or light pollution. Frequently this offers time for a

${ }^{36}$ Gruenewald, The Best of Both Worlds, p. 4. 
discussion with students that accompany me on this walk, what conservation of this untouched moorland really means. All these different aspects of the landscape as well as emotions and memories that appeared in context might illustrate how the moorland itself is not the untouched landscape we might imagine but is an ever changing environment adapting and incorporating human activity. ${ }^{37}$

During these musings it has become apparent how the landscape itself triggered emotions and feelings. The viewer within the landscape when opening all their senses turns into a subject upon which the landscape with all it facets can act upon. When engaging with the dialectical landscape the viewer hears the voice of this place as described by Lane. ${ }^{38}$ Walking in the landscape described briefly above wants the viewer to move on and see more. Walking becomes exploring and learning more about where one is. ${ }^{39}$ The landscape triggers action even in the most basic way of walking a path and being part of the rhythmic cycle giving live to a network of paths. The experiences call for action, they might motivate the walker to bring along friends or trigger the urge within locals to protect dark skies stretching above their landscapes full of cultural heritage. Suddenly the viewer has become an object to act upon the subject of landscape; to leave a mark on the stage presented by the landscape, similar to Cosgrove and Daniels idea of a landscape being a collection of material objects on a pre-existing stage or symbols represented on a provided canvas or backdrop. ${ }^{40}$

But realising that the viewer or landscape are both subject and object within time resolves the difficult concept that Lane argues as '...the place perceiving itself through us' and can actually take part in a communication with the viewer. ${ }^{41}$ Perceiving landscape purely as a collection of physical objects even if created by humans in the past or present does not allow an

\footnotetext{
${ }^{37}$ Daniel Brown, Esther Johnson and Mary Brittain, (2012), 'Work Experience at Nottingham Trent University', at http://www2.warwick.ac.uk/fac/soc/cei/centrelinkmagazine/marchcontents/workex perienceatnottinghamtrentuniversity/ [Accessed 28 March 2014].

${ }^{38}$ Belden C. Lane, 'Giving Voice to Place: Three Models for Understanding American Sacred Space', Religion \& American Culture 11, no. 1 (2001): p. 58.

39 Daniel Brown, Natasha Neale, and Robert Francis, 'Peak into the Past-An Archaeo-astronomy Summer School’, School Science Review 93, no. 342 (2011): p. 83; Daniel Brown and Lina Canas, 'Archaeoastronomy in Society: Supporting Citizenship in Schools Across Europe', International Journal for Science in Society 2, no. 3 (2010): p. 155.

${ }^{40}$ Cosgrove and Daniels, The Iconography of Landscape, p. 1.

${ }^{41}$ Tilley, Interpreting Landscapes, p. 40; Lane, Giving Voice to Place, p. 58.
}

Culture and Cosmos 
actual discussion with a landscape. Only by realising that one is part of the landscape through one's own actions and emotions over time (expressed in Greek as chronos) will it in this unrepeatable moment in time full of significance (expressed in Greek as kairos) become apparent that the landscape can indeed speak and listen, a voice and ear given to it by those who dwell within it over time becoming part of the landscape. And as Lane points out, such an 'experience (...) simultaneously in a situation of chora (place) and a moment of kairos is truly to encounter wonder' ${ }^{42}$ This could even be focused towards the instance of experiencing place through the realisation how chronos and kairos come together and resemble one of the true moments of Benjamin's dialectical image described by Auerbach. ${ }^{43}$ Such a realisation triggered by a dialectical landscape that has a constellation of moments at its heart becomes a new moment in itself. The new moment can form a constellation of moments gathered while watching and walking in a landscape. This results in the above-mentioned transient and highly temporal experience of the constellation of moments but also goes beyond a place experience towards describing a landscape as a constellation of moments.

\section{Seascape and More}

Landscape is as fluid a term as place and contains many physical and nonphysical properties and objects within, best expressed by experiencing it rather than by geographic location or outlines. So far the author has been using landscape as the general term collecting all the other scapes derived from it such as seascape, skyscape and landscape. The latter is initially defined in the traditional way. All three together were first brought to a critical attention through an art installation by Dobrowolski and Painter. ${ }^{44}$ Looking at one part of this trio of scapes, the seascape, will allow us to outline in more depth how to explore place and finally that this trio is indeed only one.

The foundations of a seascape were laid out by Westerdahl stressing that the sea should not be treated as a limit at which cultures and trading end to reappear at some other part of the coast, but that maritime cultural

\footnotetext{
${ }^{42}$ Lane, Giving Voice to Place, p. 55.

43 Auerbach, Imagine No Metaphors.

${ }^{44}$ C. Dobrowolski, C. Painter, \& Ferens Art Gallery, Landscape, Seascape, Skyscape, Escape (Kingston Upon Hull City Museums, Art Galleries \& Archives, 2002).
} 
landscape is needed and the sea itself can be a social arena. ${ }^{45}$ The term seascape was then introduced by authors such as Wehlin. ${ }^{46}$ Standing at the beach or looking over the sea from a boat it becomes clear that this scape is completely different than the traditional landscape: one cannot actually see any objects at first sight at high sea. A first step to exploring this place within a seascape would be to look below the surface to track the geography of the seabed, locate ocean currents and mark old wrecks. Here the viewer literally has to look at what lies below. People might be brought to this place by following trade routes. Such a location might also coincide with a flourishingfishing ground which is itself determined by the rhythmic coming and going of marine wild life over the seasons. And at this stage one has immersed oneself. in the ebb and flow of time to explore place. What seems so difficult to integrate in the perception of place in a landscape becomes a necessity for a place in a seascape ruled in many cases by the tides.

Noting how the water actually obscures many aspects of what makes a seascape, it is only a small step to note that the Sun with its light during the day acts in a similar way through obscuring a skyscape visible at nighttime. Like the sea rolling in with each wave covering and revealing the beach that has itself been uncovered by the outgoing tides, the rhythmic sunrise and sunset can be compared to tides, giving a skyscape an added dimension. Exploring this new aspect calls for a process of observing that embraces time, or more appropriately, watching. Discovering such cyclically revealing aspects of a skyscape assists in understanding meaning contained within them, especially expressed in concepts such as heliacal rising, the first visibility of a star after being invisible for a period of days in the morning sky before it is washed out by the incoming tide of sunlight. Discovering such a metaphorical link described above between seascape and skyscape occurred at the physical boundary of where land and sea meet, a beach. The importance of such boundaries, for example as outlined by Wehlin, has been marked by societies not only through noting tides but by also marking their landfall at certain places and marking places with monuments. There are further boundaries occurring in this trio of scapes. ${ }^{47}$ The immaterial mathematical and astronomical concept of a perfect

${ }^{45}$ Christer Westerdahl, 'The Maritime Cultural Landscape’, International Journal of Nautical Archaeology 21, no. 1 (1992): p. 6.

46 Joakim Wehlin, 'Approaching the Gotlandic Bronze Age from Sea: Future Possibilities from a Maritime Perspective’, Gothland University Press 5 (2010): p. 89.

${ }^{47}$ Wehlin, ‘Approaching the Gotlandic Bronze Age from Sea’, p. 103.

Culture and Cosmos 
horizon can be defined by where sea and sky meet. This defines when an object will rise or set in a location with a theoretical mathematical horizon most closely resembled by the sea level. This rising or setting point is a virtual place that can never be reached or a direction that can be followed. The other boundary is defined by land and sky forming the real horizon. A star setting above a mountain seen along an alignment within a monument is a real location that can in fact be visited and explored.

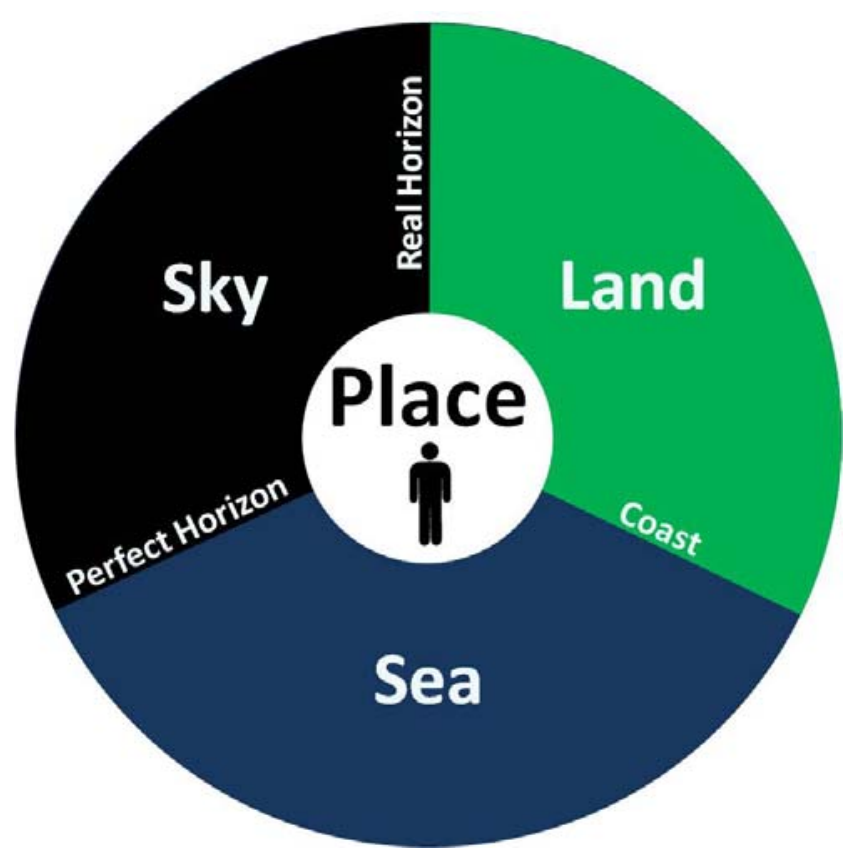

Fig. 2. The trinity of sky, land and sea representing the unity of landscape when an individual discovers place and himself in all components.

But such boundaries triggering metaphorical musings and offering moments within a dialectical landscape might not always be described by the above-mentioned physical boundaries. Recalling the experiential nature of all three scapes it can be seen that they can meet in many other places, offering us unforeseen insights. The stars or Moon reflected in the surface of a lake bring them down to Earth and turns them into object of our 
world. ${ }^{48}$ Depicting constellations seen in the sky, our societies frequently create their own land- and seascapes claiming ownership of the stars above. Viewing a valley and villages therein after night has fallen, reveals a plethora of lights weaving their patterns across the land similar to stars in the sky. By removing their own ability to view the constellations, they have themselves become a constellation of light.

Having briefly strayed into possible moments of realisation, these thoughts illustrate that the artificially created components of land-, seaand skyscape are indeed a trinity and can only be fully understood and explored when experiencing their unity as illustrated in Figure 2. This cannot occur through a scientific approach excluding as it must any emotional response, for example through observation. The exploration has to embrace the task of watching and experiencing sea, land and the sky over time. At this point, rather than describing this trinity as a landscape it has become a place in which one dwells. This realisation occurs at the moment when the human viewer realises that they are not a fourth component needed to add to the trinity, but they are already part of the land, sea, and sky around them, which is well illustrated by night time landscape installations. ${ }^{49}$ They and societies past and present are part of something bigger through their actions in time, as Tilley claims '...a pattern of activities 'collapsed' into an array of features' ${ }^{50}$ This realisation is open to everyone and reveals itself to the individual through watching. This stands in stark contrast to one of Tilley's ideas that a landscape 'cannot be understood just by introspection [and t]heir meanings and significance must be taught by some and learned by others', compared to an individual who has to encounter revelation through their own individual journey. ${ }^{51}$ This journey is not guided by a teacher but by the learner's own emotions and memories.

\section{Conclusion}

The challenge of modern archaeoastronomy in its search to discover the meaning behind alignments has been outlined. Statistical methods and pure scientific approaches can only help to a limited degree. Only by exploring

\footnotetext{
${ }^{48}$ Bernadette Brady, Dragons, Mountains and the Sky. Presentation given at the 2013 meeting of the Theoretical Archaeology Group. University of Bournemouth, 2013.

${ }^{49}$ Nina J. Morris, 'Night Walking: Darkness and Sensory Perception in a Nighttime Landscape Installation', Cultural Geographies 18, no. 3 (2011): p. 334.

${ }^{50}$ Tilley, A Phenomenology of Landscape, p. 162.

${ }^{51}$ Tilley, Interpreting Landscapes, p. 40.

Culture and Cosmos
} 
the site of an alignment in situ, within the context of the entire landscape including sea, land and sky, can the place at which the alignment was found be experienced. The concept of seascape has been used to illustrate the inherent interconnectedness of all three scapes. The place experience is supported by the process of watching and becoming aware of the passage of time, the rhythms and cycles apparent in one's surrounding. The time experience opens up an ability to emotionally connect and communicate with a landscape; at this point one truly dwells there. The concept of the dialectical landscape has been outlined as a way for viewers to negotiate a journey towards finding themselves in a landscape. In doing so, the viewer will note that time has made them part of it and its cosmic cycles.

It can be concluded that exploring one's own reflection as well as the reflection of societies and humans in the landscape makes us become part of something bigger. A meaning for an alignment can now be negotiated within the landscape with emphasis on its skyscape component that was first made significant by statistical methods. The holistic approach of watching will lead us on to listen to the voice of the landscape that was both witness and motivator to the erection of both monument and alignment. Although talking to the builders of an alignment is not possible their voices still echo in the landscape, waiting to reveal its meaning. As outlined, the dialectical landscape rejects any one truth or solution to a problem, acknowledging the importance of the individual. However, the contemporary viewer is most commonly a member of society influenced by the western scientific methodology. Therefore, it might appear fruitless to disentangle the voices of the builders of an alignment within a landscape entangled in many others voices over the millennia. Furthermore, the task becomes more challenging when heard by someone not understanding the language. But the author is confident that this is the right way to proceed, since this approach now offers a metaphorical text that can be utilised to translate and interpret, rather than a method which is limited by statistical methodology surrounded by a void of uncertainty. 